\title{
Evidence-Based Instructional Strategies in Learning Review
}

\author{
Andrew Akinmoladun* \\ Department of Physics and Technology, Bronx Community College of the City University, New York \\ Submission: July 03, 2018; Published: August 01, 2018 \\ *Corresponding author: Andrew Akinmoladun, Department of Physics and Technology, Bronx Community College of the City University, Windham \\ County Public School, Willimantic, CT, New York, Email: andrew.akinmoladun@bcc.cuny.edu
}

Keywords: Germination; Plant density; Seed quality; Water regime

\section{Introduction}

Active learning instructional strategies include a wide range of activities that normally share some common elements that entail involving students in doing things and thinking about the things they are doing [1]. Essentially, active learning must engage the learners actively as failure to do so may lead to low rates of comprehension. At the high school level, learners have already developed different learning methodologies, but the teacher should not assume they will involve themselves in active learning without being guided effectively [1]. A robotics and computer programming teacher need to guide learners closely and actively so that they can grab applicable knowledge and skills in robotics as well as computer systems and programming.

As a teacher of the said subject, learners cannot completely comprehend without being involved in real work such as programming and coding. Robotics and computer programming must involve some practical work so as to improve the rates of comprehension. More so, the teacher needs to make them think about what they are doing before they can evaluate the outcomes such as running a program through a text editor. Doing so enables the learners to understand the theory behind the practical sessions [1]. It is worth point out that active learning not only involves active engagement of the learner but also other processes and strategies such as exploring personal attitudes, thinking critically, and giving feedbacks among others as will be looked into in the following sections.

\section{Discussion}

Active learning instructional strategies encompass numerous methodologies that may be applied by a teacher or an instructor. The methodologies applied may vary from one subject to another, but the teacher should be able to choose the most effective for the learners [2]. For instance, for a robotics and computer programming teacher, he or she must be able to choose strategies that will boost the comprehension rates. Learners have negative attitudes towards robotics and computer programming and hence the teacher should be able to motivate them effectively. In order to do so, one needs to introduce topics and allow learners' time to reflect and analyze while also allowing them time to ask questions they may have [2]. More so, it is imperative to allow learners to shortly discuss among themselves the topics and concepts as a means of making them feel motivated and involved.

It is imperative to point out that active learning instructional strategies can be created and used to engage students in various processes as follows. First, they must be involved in thinking critically and creatively [2]. Robotics and computer programming is a field that calls for creative and critical thinking so that one can understand and apply the theory and basic skills learnt. For instance, computer programming starts with designing algorithms which are then translated to a computer program. In order to do so, the learners must be made to think critically and creatively. A teacher will need to motivate learners through a number of approaches such as guiding them through examples while allowing them to ask any questions, allowing group and peer discussions, and providing them with extra materials that will boost their creativity such as reference books [2]. Additionally, it is important for a teacher to ensure that the learners get rid of their negative attitudes that may hinder their creative and critical thinking.

Second, active learning can also be attained through giving and receiving feedback. This process should take place as early as learning begins so as to ensure that any issues are sorted out before they transition to bigger issues [2]. For instance, learners may want to suggest new reference materials or approaches that may seem better during class work. In this regard, the teacher should pay attention to the learners' feedbacks and suggestions which may be helpful in the whole learning process. In doing so, the teacher is able to learn about students' concerns and 
issues and hence adopt strategies and mechanisms which will effectively address their needs. Further, when an instructor or a teacher attends to suggestions and feedbacks of the learners, the latter feel motivated and inspired to learn and hence will develop a very positive attitude about the course. It is worth pointing out that receiving feedbacks from learners is one of the major ways through which the teacher and the students should communicate. Through communication, the teacher learns much about the students which is highly important [2]. However, a teacher should implement other methodologies that will improve the communication such as encouraging learners to ask more questions in class as well as making any new suggestions.

Third, active learning instructional strategies also involves involving learners in reflecting upon the learning process [3]. Learning about robotics and computer programming must involve reflection so that students will not quickly forget about concepts learnt in class. Notably, reflection should not only be done in class but also out of class. While in class, the teacher should engage learners in quick tests and note taking as a means of reflection. However, it is imperative to point out that learners should be allowed to interact among themselves so as to share concepts and ideas. While out of class, the teacher should allow interactions with the learners through emailing and should be there to answer questions that may be asked while also guiding them through personal tests and exercises as a means of reflection.

Fourth, active learning instructional strategies also involve spending greater proportion of time helping students develop their understanding and skills [3]. In robotics and computer programming learners must be made to effectively understand and gain skills. In order to attain such a goal, the teacher needs to support surface learning while also providing opportunities for learners to apply and demonstrate their understanding. Without making them demonstrate their understanding, it may be challenging for the teacher to evaluate learners' strengths and weaknesses which need to be known before going forward. Essentially, the teacher needs to be ensure that the learners completely understand the basics which are very important in the robotics and computer programming field.

For a robotics and computer programming teacher, he or she must be able to transform a traditional classroom into an interactive classroom so as to promote active learning instructional strategies. The course is about gaining skills and in-depth understanding and hence a teacher must be able to promote interactions in classrooms. In order to do so, the following approaches will need to be employed.

First, the teacher can adopt the pause procedure which normally entails promoting greater student engagement through pausing procedure where the instructor pauses for a few minutes to allow students to work in pairs to discuss concepts and rework their notes [3]. For instance, in Robotics, there are concepts such as software-hardware integration that may seem challenging to the learners. However, if learners could be allowed to discuss among themselves, it may seem easier for them to comprehend. When using the pause procedure, it imperative to point out that the instructor or the teacher should pause in intervals that will bring about the best outcomes [3]. For instance, pauses should be made after introducing new concepts and topics so as to allow learners enough time for reflecting. More so, pauses should be made to allow discussions before learners can undertake individual short tests. The pause procedure is highly effective in promoting class interactions which are highly needed in a classroom setting.

Second, the teacher can adopt the think-pair-share methodology which also promotes active interactions in learning. It often begins when information is shared through reading an assignment and then a teacher poses a single questions and students are instructed to reflect and note it through note taking [3]. They are then instructed to pair with peers so as to share their responses. The pairs can then join creating groups which then reflects and discusses their responses. The approach is very effective in making learners to get used to group work and helpful interactions that tend to promote their understanding. More so, the approach is also applicable when dealing with large classes where attending to the needs of each and every learner may not be possible during class work [3]. Further, the approach enables learners to improve their interpersonal and communication skills.

Third, the teacher can also use concept tests as an approach towards attaining active learning. In robotics and computer programming, learners should be encouraged to understand the concept as opposed to memorizing them. Concept testing enables conceptual understanding and it is done at predetermined intervals where a challenging conceptual question is posed in a multiple-choice format [4]. Learners are encouraged to work together so as to come up with the final answer collaboratively. They can share their answers and responses with other groups as a means of interaction. In order to fully promote conceptual understanding, the teacher should make a follow up and explain to learners why a certain answer is the most suitable. In case of robotics and computer programming, the teacher can offer some practical tests that aim at testing conceptual understanding.

Additionally, the teacher can implement a personal response system, which is an exciting new way of engaging learners closely. For instance, clickers can be used as avenues for facilitating personal responses. Currently, the teacher can apply other approaches that can attain better personal responses in a timely manner so that the teacher can learn about the plight of every student. It is important to note that 
personal response systems cannot work effectively while in class as they are prone to more time consuming which may not be available [4]. Hence, the teacher can make a follow up to learn more about students especially those with negative attitudes about class projects and assignments.

Further, classroom demonstrations have become subtle in teaching robotics and computer programming. A teacher needs to explicitly demonstrate about computer systems and robotics in class so that learners can harmonize theory with practicals. During introduction, demonstration may not be necessary as such, but the teacher must be able to make the learners understand what specifically the course will entail [4]. As learners gain an in-depth knowledge about computer programming and robotics, it is imperative for the teacher to demonstrate meticulously. For instance, in computer programming, the teacher must be able to demonstrate how a program is compiled and debugged. Doing so enables the learners to quickly grab what the whole procedure entails. On-screen demonstrations to the students will be most applicable. Every step and process should be explained and learners encouraged to ask questions regarding what is being demonstrated [4]. During demonstrations, the instructor or the teacher should ensure that all learners are keenly paying attention and focusing on what is being demonstrated. Doing so will allow uniformity in the learning process.

On the other hand, it is always good practice when a teacher employs illustrative excerpts in stimulating critical and creative thinking. In today's classrooms, learners are looking for new ways of doing things and hence any creativity will be welcomed warmly [4]. For instance, an illustrative excerpts may be used to explain how a certain program is compiled and debugged. More so, they can be used to explain how software and hardware relate in a robotic system. Illustrative excerpts help make the classroom lively while also making learners feel motivated and excited. In most cases, popular film excerpts and video-vignettes may be used before a concept can be explained so as to promote conceptual understanding.

In addition, use of illustrative excerpts in classroom should also involve making learners connect course content to current events. Doing so enables learners to develop a clearer sense of personal relevance and significance of the course [4]. It has been established that learners' are likely to develop a negative attitude towards a course if they feel it has no practical relevance in their daily lives. It is the duty of the teacher to make the learners connect the course content to the outside world so that they can feel the urge and need to understand the concepts introduced through the course [4]. Learners with a positive attitude are more eager and motivated to learn and hence will effectively cooperate.

Research findings have pointed out that students' concentration and focus tend to decline after 10-15 minutes of the session [4]. In this regard, it is the duty of the teacher to effectively exploit the time when learners are most attentive. This is the time when learners are most likely to understand the concepts introduced. After this time, the teacher needs to introduce demonstrations and practicals which will basically entail connecting the concepts to real work [4]. For instance, in robotics and computer programming, there are numerous concepts that need to be understood by the learners. However, the teacher needs to come up with strategies that will ensure learners are able to effectively comprehend a concept and apply through the following active learning instructional strategies.

In a classroom setting, it is important for the teacher to ensure that there are sufficient resources such as computer desktops needed for the coding. If resource-sharing is to apply, the teacher should ensure the resources have been shared optimally. More so, it is imperative for the teacher to ensure that all learners are keen and ready for the class session. A quick and random check is enough to enough to ensure that learning can begin. A teacher should not enter a classroom and immediately start introducing new concepts. Normally, he or she should first involve the teachers in some form of interaction as a means of drawing their attention to the class session.

Use of video-vignettes among other illustrative excerpts can also apply in drawing the learners' attention in a manner which does not make them feel challenged or demotivated [4]. A teacher should be able to choose materials that relate to the learners' experiences and expectations. Essentially, the teacher must hook up learners before new concepts and practices can be introduced. Doing so prepares the learners for a class session. As earlier highlighted, active learning does not only encompass methodologies applied in classroom but also approaches that aim at closely engaging the learners and making them feel motivated.

Teaching robotics and computer programming should also entail application of technological tools that will boost the learners' conceptual understanding. Currently, most high schools are already deploying technological tools in learning but have not keenly examined the applicability of those tools. In this regard, it is highly important for the teacher to choose technological tools that will help learners develop a new interest and creativity while learning. For instance, the teacher can guide the learners through internet resources that have additional information, questions, answers and links that will complement the content learnt in class [4]. However, it is imperative to point out that the teacher must discern legitimate and illegitimate sources and should guide the learners in distinguishing between the two sources. More so, the teacher can ask the learners to confirm with him or her when seeking additional resources from the internet.

It is important to note that the internet cannot be overlooked when it comes to active learning instructional 
strategies especially in courses such as robotics and computer programming [5]. The internet is a powerful tool that has diverse resources that will be applied in complementing what has been learnt in class. In order for the teacher to avoid unlikely outcomes such as learners spending time on the internet on materials that may not help them complement classroom content, he or she should guide the leaners in exploiting the internet resources [5]. More so, the teacher ought to do so in line with school's policies. Essentially, so that a teacher can effectively promote conceptual understanding, he or she must involve learners in doing things while also making them think about what they are doing.

Active learning instructional strategies are helpful in learning but lead to a number of challenges as follows. First, one cannot cover as much content within the time available [6]. This means that a teacher needs to strike a balance between using the tools and covering as much course content as possible. This can best be done through planning and scheduling which will enable effective time allocation. Second, it has been established that using the tools requires extensive pre-class preparation. A teacher should have enough time for the preparations to avoid shortcomings that may hamper effective learning. In order to prepare sufficiently, the teacher should also plan and schedule for activities [6]. Third, large class sizes have also been established as challenges to active learning instructional strategies. Employing tools such as personal response systems cannot be effective when the class size is larger than normal. In such a case, the teacher must create groups whose collective concerns and needs will be addressed during classwork [6]. Additionally, insufficient materials and equipment to support active learning instructional strategies negatively impacts the learning process. A teacher should be able to share resource available optimally among learners. Other additional challenges are students' resistance to new approaches and some teachers lacking enough time to prepare for class sessions [6]. It can be seen that most of the challenges can be addressed through school's administration collaborating with teachers to formulate working strategies.

\section{Conclusion}

Active learning instructional strategies encompass tools that aim at engaging students actively while also making them think critically about what they are doing. The strategies cannot be attained without the teacher transforming a traditional classroom into an interactive one where learners are able to interact not only with their peers but also teachers. A teacher needs to choose tools that will be applied in demonstrations and collecting feedbacks from learners as well as motivating them. Students must be motivated so as to get rid of negative attitudes that may hamper their conceptual understanding. In courses such as robotics and computer programming, the teacher must demonstrate and must involve learners in sessions that help them acquire skills as opposed to memorizing concepts. The teacher should design strategies and methodologies that will help engage learners both in classroom and outside classroom. He or she must also guide them in exploiting resources such as internet in complementing the course content. On the other hand, implementing active learning instructional strategies faces some challenges such as large class sizes, limited time, and insufficient resources and materials which must be dealt with through a teacher's collaboration with the school's administration.

\section{References}

1. Stanley C, Porter M (2002) Engaging large classes: Strategies and techniques for college Faculty. Anker Publishing, Bolton, UK.

2. Walker SE (2003) Active Learning Strategies to Promote Critical Thinking. J Athl Train 38(3): 263-267.

3. Nealy C (2005) Integrating Soft Skills Through Active Learning In The Management Classroom. Journal of College Teaching \& Learning p. 5177.

4. Eison J (2010) Using Active Learning Instructional Strategies to Create Excitement and Enhance Learning. Department of Adult, Career \& Higher Education University of South Florida 2-17.

5. Roehl A, Reddy S, Shannon G, Jett G (2013) The Flipped Classroom: An Opportunity To Engage Millennial Students Through Active Learning. Journal of Family and Consumer Sciences 105(2): 44-49.

6. Michael J (2006) Where's the evidence that active learning works? Adv Physiol Educ 30(4): 159-167.
Your next submission with Juniper Publishers will reach you the below assets

- Quality Editorial service

- Swift Peer Review

- Reprints availability

- E-prints Service

- Manuscript Podcast for convenient understanding

- Global attainment for your research

- Manuscript accessibility in different formats

( Pdf, E-pub, Full Text, Audio)

- Unceasing customer service

Track the below URL for one-step submission https://juniperpublishers.com/online-submission.php 